\title{
An exploratory study of the association between reactive attachment disorder and attachment narratives in early school-age children
}

\author{
Helen Minnis, ${ }^{1}$ Jonathan Green, ${ }^{2}$ Thomas G. O'Connor, ${ }^{3}$ Ashley Liew, ${ }^{4}$ \\ D. Glaser, ${ }^{5}$ E. Taylor, ${ }^{6}$ M. Follan, ${ }^{4}$ D. Young, ${ }^{4}$ J. Barnes, ${ }^{4}$ C. Gillberg, ${ }^{1}$ A. Pelosi, ${ }^{4}$ \\ J. Arthur, ${ }^{1}$ A. Burston, ${ }^{1}$ B. Connolly, ${ }^{1}$ and F.A. Sadiq ${ }^{1}$ \\ ${ }^{1}$ Section of Psychological Medicine, University of Glasgow, Scotland; ${ }^{2}$ University of Manchester; ${ }^{3}$ University of \\ Rochester; ${ }^{4} \mathrm{NHS}$ Greater Glosgow and Clyde; ${ }^{5}$ Great Ormond Street Hospital; ${ }^{6}$ Institute of Psychiatry
}

\begin{abstract}
Objective: To explore attachment narratives in children diagnosed with reactive attachment disorder (RAD). Method: We compared attachment narratives, as measured by the Manchester Child Attachment Story Task, in a group of 33 children with a diagnosis of RAD and 37 comparison children. Results: The relative risk (RR) for children with RAD having an insecure attachment pattern was $2.4(1.4-4.2)$ but 30\% were rated as securely attached. Within the RAD group, children with a clear history of maltreatment were more likely to be Insecure-Disorganised than children without a clear history of maltreatment. Conclusions: Reactive attachment disorder is not the same as attachment insecurity, and questions remain about how attachment research informs clinical research on attachment disorders. Keywords: Attachment, neglect, reactive attachment disorder.
\end{abstract}

Despite more than 30 years in the psychiatric nomenclature, reactive attachment disorder remains a poorly understood phenotype. Here, we consider one conceptual uncertainty, namely the link between reactive attachment disorder (RAD) and attachment insecurity. That is an issue that has attracted considerable debate (Green \& Goldwyn, 2002; O'Connor \& Zeanah, 2003a; Green, 2003) and we present novel data to examine this issue further.

\section{Attachment patterns}

Attachment patterns describe the degree to which the child is able to use the caregiver as a secure base (Ainsworth et al., 1978; Bowlby, 1982). Whereas securely attached children seek proximity with the caregiver resulting in assuagement of distress, insecurely attached children deal with the distress with little reference to the parent or in other ways do not attain efficient assuagement (Ainsworth et al., 1978). The insecure disorganised-disorientated pattern (Main \& Solomon, 1986), in which the child displays fearful or contradictory behaviours such as freezing during proximity seeking, is associated with particularly poor caregiving histories and developmental outcomes (van Ijzendoorn, Schuengel, \& BakermansKranenburgh, 1999). Importantly, none of the insecure categories is considered to be a clinical disorder but is, rather, a pattern of relationship functioning that confers later psychosocial risk (Zeanah \& Smyke, 2008).

\section{Reactive attachment disorder}

Although the concept of RAD is encapsulated in psychiatric classification systems (Table A, web appendix), the research base is scant, particularly in relation to school-age children (Sheperis, 2003) and is based almost entirely on (ex-)institutionalised samples (Levy, 1937; Goldfarb, 1945; Wolkind \& Rutter, 1973; O'Connor \& Rutter, 2000; Zeanah, 2000) - despite its presumed existence in other clinical samples. In this paper we use the term RAD as in DSM to cover both the 'inhibited' and 'disinhibited' phenotypes (World Health Organisation, 1993; American Psychiatric Association, 2000). The DSM and ICD classification systems both define RAD as being associated with early maltreatment and characterised by disinhibited behaviour (indiscriminate sociability) or by inhibited (withdrawn, hypervigilant) behaviours. There is less consensus regarding the overlap between the inhibited and disinhibited subtypes and other general questions regarding the phenotypes such as their stability and change in expression with age. Also, there are minor disagreements between nosological systems; for example, the ICD description is broader than the DSM and includes symptoms such as 'attentionseeking' and 'aggression towards self and others' (World Health Organisation, 1993; American Psychiatric Association, 2000). 


\section{Relationship between attachment insecurity and attachment disorder}

The idea that 'attachment disorder' is a disorder of the current child-parent attachment relationships may be misleading (Zeanah \& Smyke, 2008; Minnis et al., 2006; O'Connor \& Zeanah, 2003a; Green, 2003; Green \& Goldwyn, 2002). There are several conceptual and clinical reasons for suspecting that attachment disorder is quite distinct from attachment security or insecurity as conceptualised by Ainsworth, Bowlby and others. Firstly, the descriptions of RAD in DSM-IV and ICD-10 pay little attention to the literature on attachment and depict severe and pervasive socially aberrant behaviour in general rather than focusing on attachment behaviours in particular. Secondly, RAD is a description of a clinical syndrome within the child that generalises across relationship/setting rather than a description of a relationship pattern between a child and a specific caregiver. Thirdly, whereas children with an (in)secure attachment have had opportunities to form discriminating relationships, that may not be the case in children with RAD. If one regards RAD as a broader and different impairment of social functioning than insecure child-parent attachment (Green, 2003; Minnis et al., 2006), then secure attachment and RAD would not necessarily be mutually exclusive.

Progress in understanding the meaning of RAD from an attachment theory perspective depends, in the first instance, on research applying conventional attachment measures to children adopted from institutional settings who are at risk of developing RAD (Chisolm et al., 1995; O'Connor \& Zeanah, 2003b; Vorria et al., 2006). Vorria showed that approximately two years after adoption, some children reared in Greek institutions showed apparently normal attachment to a new caregiver, but higher rates of insecurity, particularly the disorganised form (Vorria et al., 2006). Chisholm similarly found that children who spent their early childhood in Romanian orphanages were significantly more at risk for insecure attachment. More challenging was their finding that some children classified as typically secure also displayed hallmark features of RAD (Chisolm et al., 1995). O'Connor et al. also found increased rates of insecure attachment in Romanian ex-institutional adoptees compared to those reared at home, but not of the typical forms of insecurity. They, too, found that some children classified as having a typical secure attachment pattern exhibited characteristic features of RAD (O'Connor et al., 2003). In a unique study, based within an institution, Zeanah and co-workers found that some children rated as having a secure attachment to an (institution) caregiver nevertheless exhibited marked RAD behaviour (Zeanah et al., 2005). In one of the only studies to assess noninstitutionalised pre-schoolers with a suspected
RAD, Boris et al. (2004) found that secure attachment classifications were reported in children with a RAD diagnosis. To summarise, several studies in exinstitutionalised or institutionalised children have now demonstrated that secure attachment can apparently coexist with RAD or RAD-like behaviours. One has demonstrated this in non-institutionalised toddlers. No study, so far, has demonstrated this in the population most likely to present to child and adolescent mental health services in developed countries: school-age children who were not reared in institutions.

\section{Measurement/developmental issues}

All existing studies of attachment security/insecurity in populations at risk for RAD used observational assessments, with most requiring some degree of modification, and assessed infants and young children. None of the studies examined mental representations of attachment relationships in this population or considered the phenomenology of attachment past early school age. This is a significant gap in the literature because of the central role that representations play in attachment assessment in at-risk populations past infancy (Hodges et al., 2003; Hodges et al., 2000; Steele et al., 2003). Attachment representations are an important focus of research because they may provide new insight into the social-cognitive processes among children with RAD - a topic about which virtually nothing is known. The current study assesses attachment representations using the Manchester Child Attachment Story Task (MCAST) (Green et al., 2000).

The measurement of attachment behaviours and relationship functioning beyond infancy has not been without controversy. Carlson et al. (Carlson, Sroufe, \& Egeland, 2004) found only modest associations between representational measures of relationship functioning in early childhood and social functioning, but a problem is that most extant research in this area concerns low-risk white, middle-class samples. Recent evidence using the MCAST in a high-risk, ethnically diverse sample has demonstrated significant associations between schoolage children's attachment narratives and conduct problems, the association with disorganisation being particularly strong (Futh et al., 2008). From the institutional and pre-school literature, we suspect that attachment classifications in school-age children with RAD are more likely to be insecure, but that some maltreated children (perhaps those with less severe maltreatment histories) may have secure attachment classifications.

We aimed to directly assess the association between RAD diagnosis and attachment patterns in early school-age children, an age-group in which there is no literature directly comparing RAD and attachment representations. 


\section{Hypotheses}

Our hypotheses were the following:

1. RAD will be associated with increased rates of attachment insecurity, but attachment security and RAD will not be mutually exclusive.

2. Children with RAD who demonstrate insecure representations of attachment are likely to have a more adverse early care history and poorer behavioural functioning compared to those who are securely attached.

\section{Methodology}

Although we followed the DSM-IV practice of considering RAD to be one disorder with two subtypes, we have based our sample recruitment around the broader set of symptoms described in ICD-10 (World Health Organisation, 1993). In the absence of preexisting tools for measuring RAD behaviours in this age-group, we have developed a protocol (see web appendix for details of development) which uses observation in the clinic waiting room, teacher report and parent interview and which allows diagnostic consensus.

\section{Sample selection}

The study was approved by the Multicentre Research Ethics Committee for Scotland. All participating adults gave informed consent and children verbal assent. Our sampling strategy aimed to produce a group of children clinically identified as having RAD behaviours and a comparison group at low risk of RAD sampled from the general population (Figure 1).

Cases. Child mental health clinical teams and social workers in the Glasgow area were asked to refer children to the study according to ICD-10 symptoms of RAD whether or not the child had a clear history of 'pathogenic care'. The omission of the requirement of a history of pathogenic care was because the nature of 'pathogenic care' remains poorly defined (Zeanah \& Smyke, 2008) and, in our clinical experience, such a history is not always easy to verify. The only exclusion criterion was verbal ability lower than that of a 4-year-old (which would preclude the child's participation in the MCAST). Children could also be excluded after assessment if the research team did not consider the child to be suffering from RAD. During approximately 1 year, 47 children with presumptive RAD were referred to us, $66 \%(n=31)$ of whom were male. Thirty-eight were considered to be suffering from RAD after clinical assessment but 5 refused to complete an MCAST, resulting in a final sample of 33 children with a diagnosis of RAD
Comparison group. We did not set out to achieve a representative sample of the general population but, rather, to achieve a group of typically developing children group matched on age and gender with the RAD group. All 217 children aged 5-8 on the case register of a moderate-sized family medical practice were identified. We used exclusion criteria based on risk indices for RAD behaviours in previous research (Millward et al., 2006): known contact with social work regarding child protection concerns (we did not exclude previous contact with child and adolescent mental health services unless there was a diagnosis of RAD), child protection registration, foster or residential care ${ }^{1}$ family practitioner perception of family dysfunction or diagnosis of RAD. Thirty-nine families were excluded on these grounds. Information packs and consent forms were sent to 178 eligible families in batches of 10, initially in random order. The balance of age and gender in cases and comparisons was reviewed at monthly research meetings. When it became clear, approximately halfway through data collection, that the mean age and proportion of males was higher in cases compared to comparisons, batches of comparison boys only were contacted in descending order of age. Fifty-four families (30\%) contacted agreed to take part. Two families could not be contacted to arrange appointments and a further 13 could not be included because the children did not meet matching criteria. Two did not complete MCASTs because of failure to attend a second appointment, therefore a total sample of 37 comparison children were included in the study.

\section{Sample description}

The case and comparison group were well matched for mean age (6.57 vs. 6.44 years) and gender (66\% vs. $67 \%$ boys) but differed on a range of other measures, including emotional and behavioural functioning, family structure and maltreatment history (see Table 1). Of the 38 children in the RAD sample, one-third $(n=12)$ were currently living in family foster care or residential care, $22 \%(n=8)$ in kinship placements, 36\% ( $n=13)$ with birth families, and a further $8 \%$ (3) with adoptive families (see Table 1). Over $60 \%(n=22)$ of the children diagnosed as having RAD had been removed from home, at some time in their lives, due to neglect. Nearly $70 \%$ $(n=23)$ of children in the RAD group had been physically and/or sexually abused while of the other $30 \%(n=12)$, all had at least one risk factor for early relationship difficulties (e.g., parental drug misuse or parental mental illness). All comparison children were living with birth parents, none had experienced

\footnotetext{
${ }^{1}$ In the UK, many children in residential care have already been in family foster care and have experienced placement breakdown. A high proportion have mental health problems (Meltzer, 2003).
} 


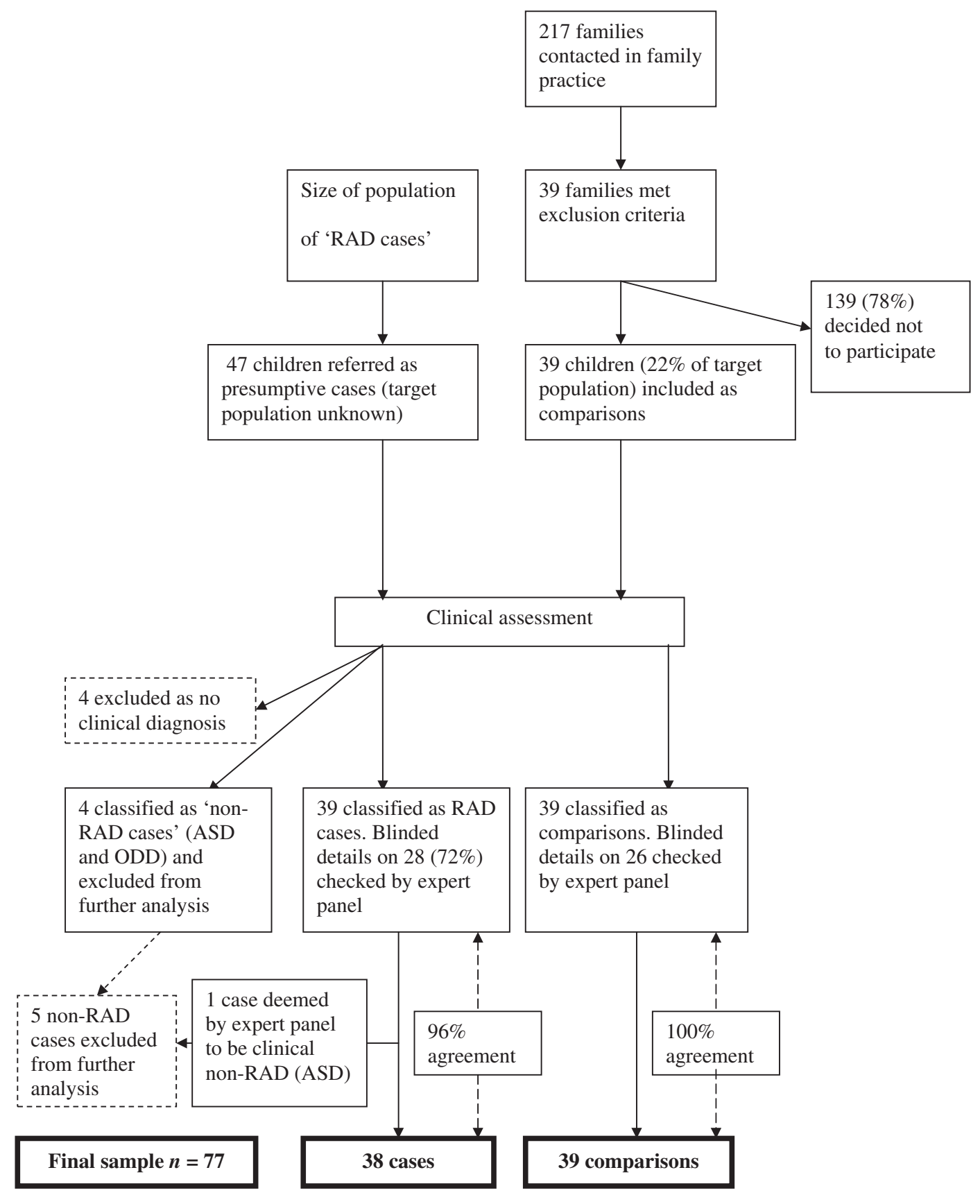

Figure 1 Recruitment diagram

adverse life events, and none were in contact with child and adolescent mental health services. Comparison children had significantly lower Strengths and Difficulties Questionnaire (SDQ) total difficulties scores compared to children with RAD (see Table 1).

\section{Measures}

Parental semi-structured interview (CAPA-RAD). A 28-item semi-structured interview for parents was developed for the study (see web appendix for details of development). The format was based on the Child and Adolescent Psychiatric Assessment (CAPA) - a well validated semi-structured parent report interview for child psychopathology used in large epidemiological studies (Angold \& Costello, 2000).

Assessment of co-morbid diagnoses - attention deficit hyperactivity disorder (ADHD), oppositional defiant disorder (ODD), conduct disorder (CD) and autism spectrum disorder (ASD) - was made using the relevant CAPA modules and the 3-di, a parental semi-structured interview for Autism Spectrum Disorder (ASD; Skuse et al., 2004).

Waiting room observation (WRO). During a 15minute episode, the child and primary caregiver were introduced to a standardised waiting room setting with which they were unfamiliar. The child was 
Table 1 Demographic details of cases and comparisons

\begin{tabular}{|c|c|c|c|c|}
\hline \multirow[b]{2}{*}{ Variable } & \multirow{2}{*}{$\frac{\text { Cases }(n=38)}{\text { Mean }(S D)}$} & \multirow{2}{*}{$\frac{\text { Comparisons }(n=39)}{\text { Mean }(S D)}$} & \multicolumn{2}{|c|}{ Statistical test } \\
\hline & & & $T$ & $p$ \\
\hline Verbal IQ (BPVS) & $96.28(10.34)$ & $102.53(9.83)$ & 2.52 & .014 \\
\hline Total Difficulties Score on parent SDQ & $22.56(5.72)$ & $6.00(5.69)$ & 10.79 & $<.0001$ \\
\hline Total Difficulties Score on teacher SDQ & $19.35(7.55)$ & $5.57(5.40)$ & 7.58 & $<.0001$ \\
\hline Parent total RPQ score & $14.38(7.00)$ & $.75(1.50)$ & 10.74 & $<.0001$ \\
\hline Teacher total RPQ score & $13.76(3.33)$ & $5.20(1.34)$ & 6.1 & $<.0001$ \\
\hline \multirow[t]{2}{*}{ Mutuality (CARP) } & $4.65(1.69)$ & $5.0(1.25)$ & .851 & .01 \\
\hline & Median & Median & & \\
\hline \multirow{2}{*}{$\begin{array}{l}\text { Socioeconomic status } \\
\text { Care placement: }\end{array}$} & 5 & 4.5 & & \\
\hline & $n=36$ & $n=38$ & & Fisher's exact \\
\hline Living with biological parent(s) & $13(36 \%)$ & $38(100 \%)$ & & $<.0001$ \\
\hline Living with adoptive parents & $3(8.3 \%)$ & 0 & & \\
\hline Living in foster or residential care & $12(33 \%)$ & 0 & & \\
\hline Living with kinship carer (relative) & 8 (22\%) & 0 & & \\
\hline \multicolumn{5}{|l|}{ Previous life events: } \\
\hline & $n=35$ & $n=38$ & & \\
\hline Current parental problems with drugs or alcohol & $1(2.9 \%)$ & 0 & & .49 \\
\hline Past parental problems with drugs or alcohol & $2(5.7 \%)$ & 0 & & .49 \\
\hline Removal from home due to neglect & $22(64.7 \%)$ & 0 & & $<.0001$ \\
\hline History of physical abuse & $14(40 \%)$ & 0 & & $<.0001$ \\
\hline History of sexual abuse & $4(11.8 \%)$ & 0 & & .04 \\
\hline $\begin{array}{l}\text { Previous known contact with child and } \\
\text { adolescent mental health services }\end{array}$ & $31(81 \%)$ & 0 & & $<.0001$ \\
\hline
\end{tabular}

*Socioeconomic status (National Statistics Classification http://www.statistics.gov.uk/methods quality/ns sec/default.asp) ranges from 1 to 8 with 1 indicating Higher Managerial and Professional occupations and 8 indicating Never Worked and Long term Unemployed.

N.B. numbers vary due to missing data.

offered drawing materials and the carer was asked to complete questionnaires (see below). Observations of indices such as shyness and interactions with strangers were made. See web appendix for details of development.

\section{Questionnaires}

The Relationship Problems Questionnaire (RPQ) is an 18-item parent-report questionnaire for RAD symptoms (Minnis, Rabe-Hesketh, \& Wolkind, 2002). It has four possible responses ('Not at all like my child', 'A bit like my child', 'Like my child' and 'Exactly like my child') scored 0, 1, 2 and 3. In a large general population sample, the RPQ had good internal consistency (Cronbach's alpha .85) (Minnis et al., 2007). A teacher version was developed for the study (see web appendix). The internal consistency for the teacher RPQ in this dataset is .92 (Cronbach's alpha).

Parents and teachers were asked to complete the Strengths and Difficulties Questionnaire, a 25-item screening instrument for common child mental health problems which has been well validated against other screening instruments (Goodman \& Scott, 1999) and against psychiatric diagnosis (Goodman, Ford, Simmons, Gatward, \& Meltzer, 2003). It has subscales for emotional problems, con- duct problems, hyperactivity, problems with peer relationships and prosocial behaviour.

\section{Assessment of attachment representations}

Children's representations of attachment were assessed using the Manchester Child Attachment Story Task (MCAST; Green et al., 2000; Green et al., 2005). The MCAST has been used in a range of studies internationally and examines attachment representations using a structured vignette completion dollplay design with attachment-specific story stems and a mood induction procedure to maximise the specificity of the child responses. Four attachmentrelated stories (hurt knee, nightmare, illness and shopping) are presented and videotaped. At the climax of each story, the child is asked to 'show me and tell me what happens next' and completes the story using the dolls. Represented attachment behaviours in the story completion are coded using a scheme conceptually derived from the Strange Situation Procedure (SSP; Ainsworth et al., 1978). In addition to codes for child attachment behaviours (such as proximity-seeking by the child doll, assuagement of distress and modulation of arousal), it includes codes for aspects of represented caregiving behaviour (such as warmth, sensitive responding or intrusiveness). Codes conceptually 
derived from the Adult Attachment Interview (AAI; Main, Kaplan, \& Cassidy, 1985) are used to rate the coherence of the represented narrative. In contrast to other doll-play measures (Oppenheim, Emde, \& Warren, 1997; Bretherton, Ridgeway, \& Cassidy, 1990), the MCAST rating system allows derivation of categorical attachment patterns as in the SSP (Green et al., 2000). The MCAST has good inter-rater reliability, stability of attachment patterns over time (Green et al., 2000) and shows concurrent validity against the AAI, Separation Anxiety Test and independent teacher ratings of child behaviour (Goldwyn et al., 2000; Futh et al., 2008).

According to a detailed coding manual (Green, Goldwyn, \& Stanley, 2005), all variables were rated on 9-point scales (generally a score of 1 indicating most optimal and 9 least optimal scores); information from individual codings were then collated to assign an attachment category (secure, insecureavoidant, insecure resistant-ambivalent or insecure disorganised); a total disorganisation ' $\mathrm{D}$ ' score was also assigned based on the number and severity of episodes of disorganised (e.g., freezing) behaviour. For certain analyses, the secure, insecure-avoidant and insecure resistant-ambivalent categories were combined to form an 'organised' category and an 'insecure' category created from the three insecure patterns. MCASTs were rated by specifically trained raters. Twenty-five percent of MCASTs $(n=18)$ were re-rated by a second rater blind to the initial rating and consensus codes used where there were discrepancies. Inter-rater reliability for 4-way MCAST attachment classifications was .93 (Kappa) and 1 for MCAST security vs. insecurity. It was possible to ascribe an attachment category to all children for whom MCASTs were available $(n=33$ cases and $n=37$ comparisons).

\section{Assessment of verbal IQ}

The British Picture Vocabulary Scale (BPVS) is a validated measure of child verbal comprehension which is well correlated with overall IQ (Atkinson, 1992).

\section{Demographic information}

Information on demographics, caregiving history and life events (including maltreatment and parental substance abuse or mental illness) was collected from parents using the relevant modules of the CAPA.

\section{Diagnosis of RAD}

Diagnosis of RAD rested upon information from parents, teachers and observation of child behaviour in the waiting room. This process is outlined in detail in the web appendix but, in brief, a prototype assessment package was developed based on existing measures used with younger children (Egger \& Angold, 2006; Goodman, Ford, Richards, Gatward, \& Meltzer, 2000; O'Connor, Bredenkamp, \& Rutter, 1999; Rushton, 1998). Research diagnoses were corroborated by a panel of experts (in child development, maltreatment and attachment- TO'C, JG, DG and ET) blind to the research team's diagnosis. Statistical reduction of the number of items, using discriminant function analysis, resulted in the 28-item CAPA-RAD semi-structured parent-report interview (taking about 15-30 minutes to administer), the Waiting Room Observation (taking 15 minutes to administer) and the 14-item RPQ questionnaire for teachers. There was good agreement (97\%; one disagreement) between the research team and expert panel on diagnostic status and, using discriminant function analysis, the CAPARAD, teacher RPQ and WRO together correctly classified $99 \%$ of cases and comparisons (see web appendix for more details).

Using ICD-10 criteria, the great majority of children with RAD had a mixed presentation of inhibited and disinhibited symptoms with 3 exceptions: two children with exclusively disinhibited symptoms and one with exclusively inhibited symptoms. We have not, therefore, attempted to separate disinhibited RAD from inhibited RAD. Of the children with RAD, $22(67 \%)$ were rated by parents as having ADHD (some were observed by us to be overactive, impulsive and inattentive while others would require further observations and reports from other informants to confirm this diagnosis). Fifteen children (45\%) were rated as having ODD (2 of these children also fulfilled criteria for conduct disorder). Three children $(9 \%)$ were rated as having an ASD. Eight children (24\%) did not fulfil criteria for any other diagnosis. None of the comparison group were rated by parents as having any diagnoses.

\section{Procedure}

Families attended on two occasions with their primary caregiver. During visit 1 , the child and caregiver were observed for 15 minutes in the waiting room using the WRO. The child then completed assessments (BPVS and/or MCAST) while the parent completed the relevant modules of the CAPA. During visit 2, the caregiver completed the 3di semi-structured interview. Each child was randomly assigned to completing the MCAST on either visit 1 or 2 according to the protocol of a nested sub-study which is not discussed here.

\section{Statistical analysis}

For comparisons of proportions we used Pearson chi-square tests and relative risks. For each selected MCAST item we employed 2-sample $t$-tests to compare the means between cases and comparisons, except for Total D Score and Conflicted Behaviour 
ratings, where we employed non-parametric tests because of skewed distributions. We used linear regression to adjust for verbal IQ (BPVS); age and gender were not included because the samples were well matched on these variables. We assessed interrater reliability using Cohen's Kappa for categorical data.

\section{Results}

We first present findings using a between-groups approach to examine differences between the RAD and non-RAD samples on the key outcome, MCAST; we then use within RAD group analyses to consider if, within the RAD group, attachment security/insecurity has additional power to predict child behavioural adjustment. Further details regarding the individual measures (CAPA-RAD, Waiting Room Observation and Teacher RPQ) used to make the diagnosis of RAD are included in the web appendix.

\section{Between group analyses: RAD and attachment representation}

Children in the comparison group had slightly higher than expected rates of secure and there were no insecure-disorganised patterns. Children in the RAD group were fairly evenly spread across the four attachment patterns, with $30 \%$ being rated as securely attached (Figure 2). The relative risk (RR) for children with RAD having an insecure pattern compared to controls was 2.4 (95\% CI 1.4-4.2; $p=.001)$.

Table 2 presents comparisons of MCAST ratings between cases and comparison children. In univariate analyses, children with RAD displayed

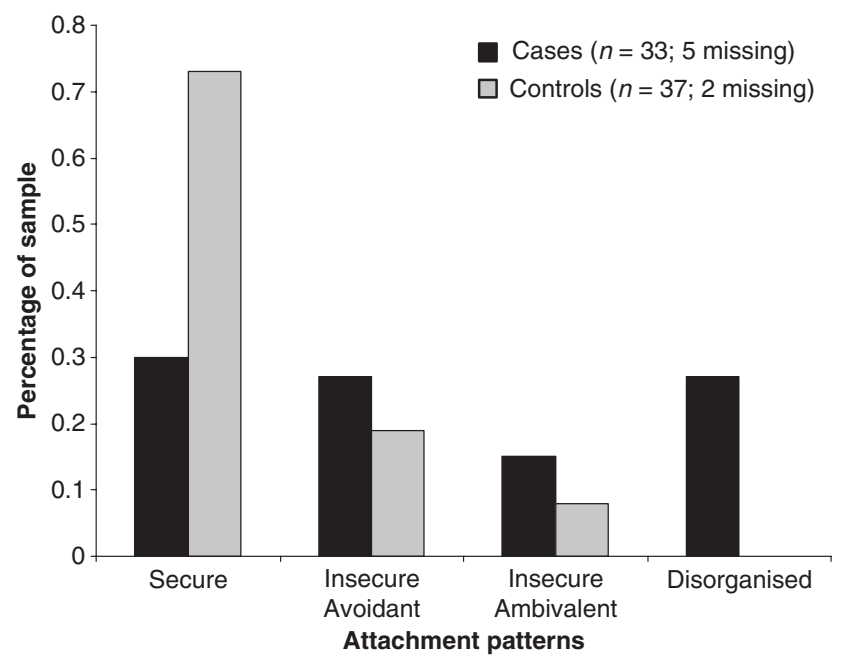

Figure 2 Attachment patterns of cases and comparisons Cases: 10 (30\%) secure; 9 (27\%) insecure avoidant; 5 $(15 \%)$ insecure ambivalent; 9 (27\%) insecure disorganised.

Comparisons: 27 (73\%) secure; 7 (19\%) insecure avoidant; 3 (8\%) insecure ambivalent; 0\% disorganised. poorer narrative coherence and their arousal was less well modulated. During the vignettes, they showed more self-care (e.g., getting their own plaster for a hurt knee) and conflicted behaviour (e.g., angry resistance to an approach from the parent). They represented the caregiving figure as showing less warmth and sensitivity and as being less involved with the child doll. Finally, children with RAD demonstrated statistically significantly higher levels of disorganised behaviours. On multivariate analyses adjusting for BPVS score, statistically significant differences were found for narrative coherence, modulation of arousal, carer sensitivity and warmth, conflicted behaviour and disorganised behaviours.

\section{Within RAD group analyses: correlates of attachment security within the RAD group}

In analyses of the RAD group alone $(n=33)$ (Table 3), children who had a clear history of maltreatment $(74 \%)$ were not significantly more likely to be insecure (avoidant, resistant-ambivalent or disorganised versus secure) ( $\mathrm{RR}=1.47(.4-4.9) ; p=$ .54), but were significantly more likely to be disorganised (disorganised versus avoidant, resistantambivalent or secure) $(\mathrm{RR}=1.6(1.1-2.2) ; p=.036)$ compared to those who did not have a clear history of maltreatment (see Table 3). Children living with biological parents $(30 \%)$ were not more likely to be insecure ( $\mathrm{RR}=1(.62-1.6) p=.98)$ or disorganised (RR $=1(.63-1.8) p=.87)$ compared to those living in substitute families. Of the 3 adopted children with RAD, two had organised insecure attachments and the third had a disorganised insecure attachment. Despite large and significant differences in SDQ scores between cases and comparisons (see Table 1), within the RAD group there was no association between attachment security and SDQ total difficulties scores as reported by parents (mean score secure vs. insecure 25.4 vs. $21.8 ; p=.18$ ) or teachers (mean score secure vs. insecure 17.8 vs. $20.6 ; p=$ .54). Effect sizes were similar for attachment disorganisation (parents: mean score organised vs. disorganised 23.7 vs. $20.00 ; p=.39$ and teachers: mean score organised vs. disorganised 18.3 vs. 23.6 ; $p=.081$ ).

Gender did differentiate within the RAD group: girls with RAD were significantly more likely to have secure patterns than boys $(\mathrm{RR}=2.7(1.1-6.9) p=$ .032) and there was a trend towards girls having more organised patterns $(\mathrm{RR}=3.7(.5-25) p=.097)$ compared to boys. This gender difference was not explained by verbal IQ.

\section{Discussion}

This is the first study to consider attachment quality in RAD in terms of narrative representations. Our findings confirm that while children with RAD are at 
Table 2 Comparisons of MCAST ratings between cases $(n=33)$ and comparisons $(n=37)$

\begin{tabular}{|c|c|c|c|c|c|c|c|c|}
\hline & \multirow[b]{2}{*}{ RAD } & \multirow[b]{2}{*}{ No RAD } & \multicolumn{3}{|c|}{ Unadjusted } & \multicolumn{3}{|c|}{ Adjusted for BPVS score } \\
\hline & & & $\begin{array}{c}\text { Difference in } \\
\text { scores }\end{array}$ & $95 \% \mathrm{CI}$ & $\begin{array}{c}p \\
\text { value }\end{array}$ & $\begin{array}{c}\text { Difference in } \\
\text { scores }\end{array}$ & $95 \%$ CI & $p$ value \\
\hline Narrative Coherence $^{+}$ & 4.90 & 6.13 & 1.23 & $(1.95, .51)$ & .001 & 1.24 & $(2.02, .45)$ & .003 \\
\hline Arousal $^{+}$ & 6.80 & 7.40 & .60 & $(1.07, .12)$ & .014 & .65 & $(1.09, .21)$ & .004 \\
\hline Self care $^{+}$ & .95 & .55 & .40 & $(.06, .74)$ & .021 & .51 & $(.50,1.53)$ & .317 \\
\hline Carer Sensitivity \& Warmth ${ }^{+}$ & 3.44 & 5.30 & 1.86 & $(3.07, .65)$ & .003 & 1.34 & $(2.65, .34)$ & .045 \\
\hline 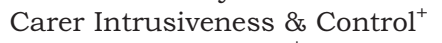 & 2.66 & 3.81 & 1.15 & $(1.92, .37)$ & .004 & .77 & $(1.59, .05)$ & .065 \\
\hline Conflicted Behaviour ${ }^{*}$ & 1.25 & 1.00 & .25 & $(0, .75)$ & .004 & 1.03 & $(.27,1.79)$ & .008 \\
\hline Total D Score* & 2.25 & 1.00 & 1.25 & $(.5,1.75)$ & $<.0001$ & 1.57 & $(.78,2.37)$ & $<.0001$ \\
\hline
\end{tabular}

${ }^{+}$Difference in mean scores (on 9 point scale). ${ }^{*}$ Difference in median scores (on 9 point scale).

Table 3 Maltreatment versus security/insecurity and organisation/disorganisation (RAD group only; $n=33$ )

\begin{tabular}{|c|c|c|c|c|c|c|}
\hline & \multicolumn{3}{|c|}{$\begin{array}{l}\text { Security (insecure resistant ambivalent, } \\
\text { insecure avoidant or insecure } \\
\text { disorganised versus secure) }\end{array}$} & \multicolumn{3}{|c|}{$\begin{array}{l}\text { Organisation (insecure disorganised versus } \\
\text { insecure avoidant, insecure } \\
\text { resistant ambivalent or secure) }\end{array}$} \\
\hline & $\begin{array}{l}\text { Number } \\
\text { secure }\end{array}$ & $\begin{array}{l}\text { Number } \\
\text { insecure }\end{array}$ & $\begin{array}{c}\text { Relative risk and } \\
\quad p \text { value }\end{array}$ & $\begin{array}{l}\text { Number } \\
\text { organised }\end{array}$ & $\begin{array}{c}\text { Number } \\
\text { disorganised }\end{array}$ & $\begin{array}{l}\text { Relative risk } \\
\text { and } p \text { value }\end{array}$ \\
\hline $\begin{array}{l}\text { Maltreatment (\%) (physical/sexual } \\
\text { abuse or removal from home } \\
\text { because of neglect) }\end{array}$ & $6(26 \%)$ & 17 (74\%) & $\begin{array}{c}\mathrm{RR}=1.47(.44 .9) \\
p=.540\end{array}$ & $14(61 \%)$ & 9 (39\%) & $\begin{array}{c}\mathrm{RR}=1.6\left(\begin{array}{ll}1.12 .2 \\
p=.036\end{array}\right.\end{array}$ \\
\hline Maltreatment absent (\%) & $3(37 \%)$ & $5(63 \%)$ & & $8(100 \%)$ & $0(0 \%)$ & \\
\hline
\end{tabular}

greater risk of insecure attachment, a sizable minority $(30 \%)$ of children diagnosed as having RAD according to clinical interview were independently rated as demonstrating a secure attachment on a narrative assessment; organised insecure patterns were found in an additional $42 \%$. On the other hand, the rate of disorganised attachments were elevated, and higher than would be expected in the general population (van Ijzendoorn et al., 1999; Sroufe, 2005).

An important conceptual/methodological puzzle is why apparently typical patterns of attachment especially secure ones - are observed in narratives of children for whom there is clinical data suggesting RAD. One explanation would be that insecure attachment represents less optimal current functioning in children with RAD. This hypothesis did not receive support in this study because SDQ scores did not differentiate secure from insecure or disorganised from organised in this sample. This might suggest that attachment security has a different meaning in the context of RAD, or that MCAST ratings may not be valid measures of attachment in this very disturbed group. These possibilities require future investigation.

Our second hypothesis addressed whether secure children with RAD would have a different care history from insecure children with RAD. In this case, some interesting patterns emerged. A small group of our children with RAD did not have a clear history of maltreatment, at least according to the clinical data that were available to us. This is reminiscent of data from the ERA study that found that a small minority of children who did not experience early deprivation exhibited significant disinhibited behaviour (O'Connor \& Rutter, 2000); the authors of the ERA study raised the possibility that this apparent anomaly was explained by method/measurement error. In our sample, the measurement error seems a less likely explanation because children without documented severe maltreatment were more likely to show an organised strategy in the MCAST; children with documented maltreatment were more likely to be rated as having a disorganised narrative. The association between attachment disorganisation and maltreatment is well documented in high- and normal-risk samples (Green \& Goldwyn, 2002; van Ijzendoorn \& Bakermans-Kranenburg, 2003; Futh et al., 2008); our findings extend that work by showing that disorganisation may be a useful marker even in a group with suspected RAD.

As expected, the narrative representations of children with RAD were reliably different from children in the comparison group in several aspects. The poorer narrative coherence and higher levels of disorganisation reflect the higher prevalence of insecure (particularly disorganised) attachment in this group. The RAD group had poorer modulation of arousal and were more likely to show lack of carer sensitivity and warmth but more conflicted behaviours compared to the comparison group. This fits well with our clinical impressions that children with RAD often have problems with speech and language functioning, exhibit poor affect regulation and may perceive 
their caregivers negatively. It is of note that these findings remained significant after accounting for cognitive measures, suggesting that the disturbance found in the MCAST is not merely a proxy for cognitive or language problems but something more particular to attachment relationships. What remains uncertain is the extent to which the narrative assessment can be seen as an 'accurate' portrayal or representation by the children with RAD. In other words, do children with RAD accurately perceive receiving less parental warmth or do they fail to detect and represent warmth that they do receive - perhaps because of problems in information processing. We are unable to differentiate these two possibilities, but underscore this as an area needing further study.

The gender differences in attachment security in the children with RAD are intriguing and were not explained by differences in verbal IQ. In previous research, we have found that RAD behaviours appear to be more strongly determined by genetic factors in boys and by shared environment in girls (Minnis et al., 2007). These findings reinforce the notion that further exploration of gender differences in RAD and attachment is warranted.

Our study is limited by the relatively small sample size and by biases in recruitment of both groups. The comparison group, because of the relatively low response rate, appear better functioning than the general population, reflected in the slightly higher prevalence of secure attachment compared to general population studies (Sroufe, 2005). We do not know the population prevalence of RAD, but the fact that most of our RAD sample was recruited through child and adolescent psychiatry may have biased this group towards children with more burdensome difficulties. Diagnostic controversies regarding RAD remain (Prior \& Glaser, 2006), particularly beyond pre-school age (AACAP Official Action, 2005). Although we have drawn on the best available existing measures for RAD and achieved diagnostic consensus, our measures for RAD will undoubtedly be further developed over the years as understanding of RAD changes. It may be interesting, in future research, to examine associations between attachment patterns and the disihibited and inhibited subtypes of RAD, but as the great majority of children in our sample had a mixed profile of symptoms this was not possible in our study. Strengths of this study lie in its systematic and purposive sampling for RAD, its use of an assessment protocol which, while still under development, is as well standardised as possible in the current state of knowledge about RAD, and use of a validated representational measure of attachment that avoids measurement confound between behaviours coding for the disorder and the attachment pattern itself.

Measurement difficulties are an important consideration in attachment research with highly disturbed samples, such as those with RAD and related disturbances (Chisolm et al., 1995; O'Connor, 2005). For example, in Vorria's Greek institutionalised sample, $8 \%$ of young children had unclassifiable attachment patterns (Vorria et al., 2006). None of the children in our sample were unclassifiable, however, and we did not rate children as 'secure' on the MCAST unless there was a clear demonstration of proximity-seeking with the 'mummy-doll' and resolution of the distress in the context of caregiving. Our high inter-rater reliability on the MCAST gives us some confidence in our measurement of these secure representations and we suspect that the MCAST may be a useful attachment measure in this population. Story stem techniques are readily usable in clinical practice and, if they can reveal such complementary information, may be a useful adjunct to traditional clinical diagnosis. However, further research may reveal useful additional codes to describe attachment behaviour in this particularly disturbed sample.

\section{Conclusions}

Our findings reinforce the conclusions from other literature that RAD is a phenomenon different in kind from attachment specific behaviours. The nature of the early disruption experienced by many children with RAD has been very severe and RAD may represent a more pervasive and diffuse disruption of social development than the relatively discrete and dyadic-specific alterations in goal-directed behaviours conceptualised in classic attachment theory. An important task of future research will be to gain a better understanding of attachment in the context of RAD, including the possibility that there may be differences in behaviour even within the 'secure' category. RAD can perhaps be seen as one of the pervasive disorders of social impairment in the nosology. The nature of the neurobiological mechanisms underlying this impairment and their associations with the developmental phenomenology of the syndrome are priorities for future research.

\section{Supporting information}

Additional Supporting Information may be found in the online version of this article:

Table A, Appendix. (Word document)

Please note: Wiley-Blackwell are not responsible for the content or functionality of any supporting materials supplied by the authors. Any queries (other than missing material) should be directed to the corresponding author for the article.

\section{Acknowledgements}

The study was funded by the Chief Scientist Office of the Scottish Executive. We are grateful to the 
participants and to the clinicians and parents who contributed to the development of the assessment protocol for RAD. We are particularly grateful to Charles Zeanah, Anna Smyke and Neil Boris for their advice about the design of the study during a visit by HM to New Orleans in August 2004.

\section{Correspondence to}

Helen Minnis, Section of Psychological Medicine, University of Glasgow, Caledonia House, Yorkhill Hospital, Glasgow G38SJ, Scotland; Email: h.minnis@ clinmed.gla.ac.uk

\section{Key points}

- Pre-schoolers have been reported to have secure attachment patterns yet have symptoms of reactive attachment disorder (RAD).

- RAD symptoms can be reliably identified in school-age children although co-morbid symptoms, particularly of ADHD, are common.

- Children with RAD symptoms were at more than twice the risk of having an insecure attachment pattern compared to typically developing comparison children, but $30 \%$ were rated as having a secure attachment pattern.

- Because secure attachment and RAD can co-occur, both attachment patterns and symptoms of RAD should be considered when assessing children who have experienced early maltreatment.

- Narrative assessments of attachment may identify features of child relationships that are not otherwise clinically detectable.

\section{References}

AACAP Official Action. (2005). Practice parameter for the assessment and treatment of children and adolescents with reactive attachment disorder in infancy and early childhood. Journal of the American Acad emy of Child and Adolescent Psychiatry, 44, 12061219.

Ainsworth, M.D.S., Blehar, M.C., Waters, E., \& Wall, S. (1978). Patterns of Attachment. Hillsdale, NJ: Lawrence Erlbaum.

American Psychiatric Association. (2000). Diagnostic and statistical manual of mental disorders (Rep. No. Fourth Edition Revised). Washington, DC: American Psychiatric Association.

Angold, A., \& Costello, E.J. (2000). The Child and Adolescent Psychiatric Assessment (CAPA). Journal of the American Academy of Child and Adolescent Psy chiatry, 39, 39-48.

Atkinson, L. (1992). The British Picture Vocabulary Scale. British Journal of Disorders of Communication, 26, 369-372.

Boris, N.W., Hinshaw-Fuselier, S.S., Smyke, A.T., et al. (2004). Comparing criteria for attachment disorders: Establishing reliability and validity in high-risk samples. Journal of the American Academy of Child and Adolescent Psychiatry, 43, 568-577.

Bowlby, J. (1982). Attachment. Volume 1: Attachment and loss (2nd edn). London: Hogarth Press.

Bretherton, I., Ridgeway, D., \& Cassidy, J. (1990). Assessing internal working models of the attachment relationship: An attachment story completion task for 3-year-olds. In M.T. Greenbergh, D. Cicchetti, \& E.M. Cummings (Eds.), Attachment in the preschool years (pp. 273-308). Chicago: University of Chicago Press.

Carlson, E.A., Sroufe, L.A., \& Egeland, B. (2004). The construction of experience: A longitudinal study of representation and behavior. Child Development, 75 , 66-83.
Chisolm, K., Carter, M.C., Ames, E.W., \& Morison, S.J. (1995). Attachment security and indiscriminately friendly behaviour in children adopted from Romanian Orphanages. Development and Psychopathol ogy, 7, 283-294.

Egger, H.L., \& Angold, A. (2006). The Preschool Age Psychiatric Assessment: A structured parent interview for diagnosing psychiatric disorders in preschool children. In R. Delcarmen-Wiggens, \& A. Carter (Eds.), Handbook of infant and toddler mental health assessment (pp. 223-243). New York: Oxford University Press.

Futh, A., O'Connor, T., Matias, C., Green, J., \& Scott, S. (2008). Attachment narratives and behavioral/emotional symptoms in an ethnically diverse, at-risk sample. Journal of the American Academy of Child and Adolescent Psychiatry, 47, 709-718.

Goldfarb, W. (1945). Effects of psychological deprivation in infancy and subsequent stimulation. American Journal of Psychiatry, 102, 18-33.

Goldwyn, R., Stanley, C., Smith, V., \& Green, J. (2000). The Manchester Child Attachment Story Task: Relationship with parental AAI, SAT and child behaviour. Attachment and Human Development, 2, 71-84.

Goodman, R., Ford, T., Richards, H., Gatward, R., \& Meltzer, H. (2000). The Development and Well-Being Assessment: Description and initial validation of an integrated assessment of child and adolescent psychopathology. Journal of Child Psychology and Psy chiatry, 41, 645-656.

Goodman, R., Ford, T., Simmons, H., Gatward, R., \& Meltzer, H. (2003). Using the Strengths and Difficulties Questionnaire (SDQ) to screen for child psychiatric disorders in a community sample. International Review of Psychiatry, 15, 166-172.

Goodman, R., \& Scott, S. (1999). Comparing the Strengths and Difficulties Questionnaire and the Child Behavior Checklist: Is small beautiful? Journal of Abnormal Child Psychology, 27, 17-24. 
Green, J.M. (2003). Are attachment disorders best seen as social impairment syndromes? Attachment and Human Development, 5, 259-264.

Green, J., \& Goldwyn, R. (2002). Annotation: Attachment disorganisation and psychopathology: New findings in attachment research and their potential implications for developmental psychopathology in childhood. Journal of Child Psychology and Psychia try, 43, 835-846.

Green, J., Goldwyn, R., \& Stanley, C. (2005). Coding manual for the Manchester Child Attachment Story Task. Unpublished manuscript.

Green, J., Stanley, C., Smith, V., \& Goldwyn, R. (2000). A new method of evaluating attachment representations in the young school age children: The Manchester Child Attachment Story Task (MCAST). Attachment and Human Development, 2, 48-70.

Hodges, J., Steele, M., Hillman, S., et al. (2003). Changes in attachment representations over the first year of adoptive placement: Narratives of maltreated children. In Clinical child psychology and psychiatry (pp. 351-387). London: Sage Publications.

Hodges, J., Steele, M., Hillman, S., Henderson, K., \& Neil, M. (2000). Effects of abuse on attachment representations: Narrative assessments of abused children. Journal of Child Psychotherapy, 26, 433-455.

Levy, D.M. (1937). Primary affect hunger. American Journal of Psychiatry, 94, 643-652.

Main, M., Kaplan, N., \& Cassidy, J. (1985). Security in infancy, childhood and adulthood: A move to the level of representation. In I. Bretherton, \& E. Waters (Eds.), Growing points of attachment theory and research. Monographs of the Society for Research in Child Development, 50(1-2, Serial No. 209), 66-104.

Main, M., \& Solomon, J. (1986). Discovery of an insecure-disorganized/disorientated attachment pattern. In M. Yogman, \& T.B. Brazleton (Eds.), Affective development in infancy (pp. 95-124). Norwood, NJ: Ablex.

Meltzer, H. (2003). The mental health of young people looked after by local authorities in England. London: HMSO.

Millward, R., Kennedy, E., Towlson, K., \& Minnis, H. (2006). Reactive attachment disorder in looked after children. Emotional and Behavioural Difficulties, 11, 273-279.

Minnis, H., Everett, K., Pelosi, A., Dunn, J., \& Knapp, M. (2006). Children in foster care: Mental health, service use and costs. European Child and Adolescent Psychiatry, 15, 70.

Minnis, H., Rabe-Hesketh, S., \& Wolkind, S. (2002). Development of a brief, clinically relevant, scale for measuring attachment disorders. International Journal of Methods in Psychiatric Research, 11, 90-98.

Minnis, H., Reekie, J., Young, D., O'Connor, T., Ronald, A., Gray, A., et al. (2007). Genetic, environmental and gender influences on attachment disorder behaviours. British Journal of Psychiatry, 190, 495.

O'Connor, T.G. (2005). Attachment disturbances associated with early severe deprivation. In C.S. Carter, L.
Ahnert, K.E. Grossmann, S.B. Hrdy, \& M.E. Lamb (Eds.), Attachment and bonding: A new synthesis (pp. 257-267). Cambridge, MA: MIT Press.

O'Connor, T., Bredenkamp, D., \& Rutter, M. (1999). Attachment disturbances and disorders in children exposed to severe early deprivation. Infant Mental Health Journal, 20, 10-29.

O'Connor, T.G., Marvin, R.S., Rutter, M., et al. (2003). Child-parent attachment following early institutional deprivation. Development and Psychopathology, 15, 19-38.

O'Connor, T., \& Rutter, M. (2000). Attachment disorder behavior following early severe deprivation: Extension and longitudinal follow-up. Journal of the American Academy of Child and Adolescent Psychiatry, 39, 703-712.

O'Connor, T.G., \& Zeanah, C.H. (2003a). Attachment disorders: Assessment strategies and treatment approaches. Attachment and Human Development, $5,223-244$.

O'Connor, T.G., \& Zeanah, C.H. (2003b). Introduction to the special issue: Current perspectives on assessment and treatment of attachment disorders. Attach ment and Human Development, 5, 221-222.

Oppenheim, D., Emde, R.N., \& Warren, S. (1997). Children's narrative representations of mothers: Their development and associations with child and mother adaptation. Child Development, 68, 127-138.

Prior, V., \& Glaser, D. (2006). Two versions of attachment disorder. In Understanding attachment and attachment disorders (pp. 183-187). London: Jessica Kingsley.

Rushton, A. (1998). Measuring outcomes for children late-placed for adoption. Children and Society, 12, 190-191.

Sheperis, C.J., Doggett, R.A., Hoda, N.E., et al. (2003). The development of an assessment protocol for reactive attachment disorder. Journal of Mental Health Counseling, 25, 291-310.

Skuse, D., Warrington, R., Bishop, D., et al. (2004). The Developmental, Dimensional and Diagnostic Interview (3di): A novel computerized assessment for autism spectrum disorders. Journal of the American Academy of Child and Adolescent Psychiatry, 43, 548-558.

Sroufe, L.A. (2005). Attachment and development: A prospective, longitudinal study from birth to adulthood. Attachment and Human Development, 7, 349367.

Steele, M., Hodges, J., Kaniuk, J., et al. (2003). Attachment representations and adoption: Associations between maternal states of mind and emotion narratives in previously maltreated children. Journal of Child Psychotherapy, 29, 187-205.

van Ijzendoorn, M.H., \& Bakermans-Kranenburg, M.J. (2003). Attachment disorders and disorganized attachment: Similar and different. Attachment and Human Development, 5, 313-320.

van Ijzendoorn, M.H., Schuengel, C., \& BakermansKranenburgh, M.J. (1999). Disorganized attachment in early childhood: Meta-analysis of precursors, concomitants, and sequelae. Development and Psycho pathology, 11, 225-249.

Vorria, P., Papaligoura, Z., Sarafidou, J., Kopakaki, M., Dunn, J., van Ijzendoorn, M.H., et al. (2006). The 
development of adopted children after institutional care: A follow-up study. Journal of Child Psychology and Psychiatry, 47, 1246-1254.

Wolkind, S., \& Rutter, M. (1973). Children who have been 'in care' - an epidemiological study. Journal of Child Psychology and Psychiatry, 14, 97-105.

World Health Organisation. (1993). The ICD 10 classification of mental and behavioural disorders: Diagnostic criteria for research. Geneva: World Health Organisation.

Zeanah, C. (2000). Disturbances of attachment in young children adopted from institutions. Journal of
Developmental and Behavioral Pediatrics, 21, 230236.

Zeanah, C., \& Smyke, A. (2008). Attachment disorders in family and social context. Infant Mental Health Journal, 29, 219-233.

Zeanah, C.H., Smyke, A.T., Koga, S.F., \& Carlson, E. (2005). Attachment in institutionalized and community children in Romania. Child Development, 76, 1015-1028. 